\title{
How Do You Want Your Eggs?
}

\author{
Mario T. DiDea, RT(N) \\ Montefiore Medical Center, New York, New York
}

$\mathbf{I}$

the spring of 2018, my institution expected the triennial survey by The Joint Commission (TJC). In preparation for the visit, several mock surveys were conducted to identify any deficiencies in advance. On the very first mock inspection of the nuclear medicine department, the surveyor inquired about our egg preparation process for gastric emptying scintigraphy (GES). To my surprise, he pointed out the need to verify whether our cooking process kills off Salmonella in the egg whites.

This was news to me-and one of those "what the heck!" moments. Other than package inserts and the consensus guideline related to radiolabeling of the egg whites, I had never seen any regulations regarding egg preparation. Our protocol simply states to cook the egg whites with ${ }^{99 \mathrm{~m}}$ Tc-labeled sulfur colloid (1).

However, this is what TJC does. No, I do not mean make our lives difficult. Rather, the goal of TJC is to identify potential safety and patient care violations and make recommendations on how we can achieve compliance. The nuclear medicine department is subject to the same overarching risk-reduction rules as other departments, such as the dietary department and the blood bank.

To address this issue, we wasted no time contacting our institution's dietary supervisor, who assisted us in creating a safe egg-cooking procedure that would satisfy a potential TJC surveyor. Actually, the process was much more straightforward than one might think. First, we established a microwave cooking time of 2 min to bring the egg whites to a minimum internal cooking temperature of $71^{\circ} \mathrm{C}\left(160^{\circ} \mathrm{F}\right)$. Temperature is measured by inserting the probe directly into the cooked egg whites. Although a cooking time of $2 \mathrm{~min}$ is the setting we use, each nuclear medicine department will have to establish its own minimum cooking time to produce firm eggs at or above $71^{\circ} \mathrm{C}\left(160^{\circ} \mathrm{F}\right)$. Next, we established a periodic quality control procedure for the digital thermometer to verify proper functioning. We decided to perform a quarterly check using an egg white preparation $\left(>71^{\circ} \mathrm{C}\left[160^{\circ} \mathrm{F}\right]\right)$ and ice water $\left(0^{\circ} \mathrm{C}\left[32^{\circ} \mathrm{F}\right]\right)$. Finally, we updated our written GES procedure and notified all nuclear medicine technologists about the changes.

One Monday morning in June, the increased activity and strange faces milling about the facility lobby indicated "they" were here; TJC was onsite for an inspection. On day 2, surveyors visited one of our nuclear medicine sites. To no one's surprise, the surveyor questioned the egg-cooking method. After listening to the lead technologist's explanation, the surveyor looked up amazed and said, "You stole my thunder!" Our institution's administrator was present for the exchange and could not have been more pleased with the results.

Before going any further, I would like to explain, in greater detail, the egg preparation process being used in my institution. First, we confirm

Received Jan. 29, 2019; revision accepted Mar. 13, 2019.

For correspondence or reprints contact: Mario T. DiDea, Montefiore Medical Center, 340 E. 66th St., Apt. 6C, New York, NY 10065.

E-mail: nukemario@gmail.com

Published online Apr. 24, 2019.

COPYRIGHT (c) 2019 by the Society of Nuclear Medicine and Molecular Imaging. DOI: $10.2967 /$ jnmt.119.226829 that at least $4 \mathrm{~h}$ have elapsed from the last meal the patient consumed. In a microwave-proof container, approximately $118 \mathrm{~mL}$ (4 oz) of liquid egg whites are combined with $37 \mathrm{MBq}(1 \mathrm{mCi})$ of ${ }^{99 \mathrm{~m}} \mathrm{Tc}$-sulfur colloid. The egg is placed in the container first, and then the ${ }^{99 \mathrm{~m}} \mathrm{Tc}$-sulfur colloid is distributed throughout (not just squirted in one place). The mixture is stirred for at least $1 \mathrm{~min}$, covered, and placed into a dedicated microwave oven. Cooking time is set for $120 \mathrm{~s}$, with a pause at $1 \mathrm{~min}$ to stir the mixture again. The egg whites are cooked until they achieve a firm consistency with no liquid visible. They are served with 2 slices of bread, $120 \mathrm{~mL}$ of water, and $30 \mathrm{~g}$ of jelly. Patients are encouraged to consume the entire meal within $10 \mathrm{~min}$.

My story does not end there. In June 2018, I attended the Society of Nuclear Medicine and Molecular Imaging (SNMMI) annual meeting in Philadelphia, and I had the opportunity to share this story with fellow technologists. One colleague shared an even more elaborate requirement for preparing the radiolabeled egg whites using a frying pan. At that facility, the chef $d u$ jour must don a mask and hairnet while cooking, followed by vigorous cleaning of the pan and utensils using a disposable sponge (single-use)

Some of you may be realizing that your current egg-cooking method is not up to snuff. Indeed, there are reports of nuclear medicine departments out there using everything from sticky buns to oatmeal, nutrition shakes, and good ole chicken livers instead of egg whites for GES. However, I caution you to make sure your cooking method meets TJC safety requirements along the SNMMI procedure guidelines for GES (2).

In addition, the new SNMMI Connect community is a good source of information about the experiences of other nuclear medicine departments not only with GES but with all things nuclear medicine. I encourage you to take a peek. If you lean more toward the academic side, I can recommend 3 helpful GES articles, which are listed in the references (3-5).

If you have not been visited by TJC in a year or so, be ready to take your cooking up a notch!

\section{DISCLOSURE}

No potential conflict of interest relevant to this article was reported.

\section{REFERENCES}

1. Abell TL, Camilleri M, Donohoe K, et al. Consensus recommendations for gastric emptying scintigraphy: a joint report of the American Neurogastroenterology and Motility Society and the Society of Nuclear Medicine. J Nucl Med Technol. 2008;36:44-54.

2. Donohoe KJ, Maurer AH, Ziessman HA, et al. Procedure guideline for adult solidmeal gastric-emptying study 3.0. J Nucl Med Technol. 2009;37:196-200.

3. Bonta DV, Brandon DC, Hernandez J, Patel M, Grant S, Alazraki N. Clinical intervention for quality improvement of gastric-emptying studies. J Nucl Med Technol. 2014;42:274-277.

4. Knight LC. Update on gastrointestinal radiopharmaceuticals and dosimetry estimates. Semin Nucl Med. 2012;42:138-144.

5. Farrell MB, Costello M, McKee JD, Gordon LL, Fig LM. Compliance with gastric-emptying scintigraphy guidelines: an analysis of the Intersocietal Accreditation Commission database. J Nucl Med Technol. 2017;45:6-13. 